EM

\title{
RELAÇÕES TRANSFRONTEIRIÇAS ENTRE O OESTE CATARINENSE (BR) E A REGIÃO DE MISIONES (ARG): ASSOCIAÇÃO ENTRE O TRABALHO DE CAMPO E O ENSINO DE GEOGRAFIA ${ }^{1}$
}

\section{CROSS-BORDER RELATIONS BETWEEN THE WEST CATARINESE (BR) AND THE MISSION REGION (ARG): ASSOCIATION BETWEEN FIELD WORK AND TEACHING GEOGRAPHY}

\section{RELACIONES TRANSFRONTERIZAS ENTRE EL OESTE CATARINENSE (BR) Y REGIÓN DE MISIONES (ARG): ASOCIACIÓN ENTRE TRABAJO DE CAMPO Y ENSEÑANZA DE GEOGRAFÍA}

\author{
Gerson Junior NAIBO ${ }^{2}$ \\ Shara BRUNETTO ${ }^{3}$ \\ Marlon BRANDT ${ }^{4}$
}

\begin{abstract}
Resumo: Este artigo tem por objetivo, analisar e compreender a importância do trabalho de campo na formação acadêmica dos profissionais que atuam na área do ensino de Geografia, assim como, conhecer a construção das distintas realidades fronteiriças entre Brasil e Argentina, da mesma maneira que os aspectos culturais da população. Estudar a fronteira, por meio da análise de campo, é fundamental para compreender o seu processo de povoamento e formação, como para entendimento das relações que são estabelecidas entre os territórios. Nesse sentido, utilizamos como estudo de caso as atividades realizadas durante o trabalho do campo da disciplina de Geografia Política, do Curso de Graduação em Geografia - Licenciatura, da Universidade Federal da Fronteira Sul, Campus Chapecó. Através do trabalho de campo, tornou-se possível compreender as diferentes relações entre as fronteiras, bem como ampliar o conhecimento em suas múltiplas dimensões, possibilitando assim, a relação entre as diferentes áreas da Geografia, desde as mais próximas até as mais distantes. Neste caso, há uma aproximação intrínseca entre o sujeito e o território estudado, ampliando as capacidades de compreensão das dinâmicas territoriais. Deste modo, podemos salientar que o trabalho de campo é essencial para ampliar o conhecimento, dando elementos sólidos para a formação dos geógrafos.
\end{abstract}

Palavras-Chave: Ensino de Geografia; Caminhos pedagógicos; Trabalho de campo; Fronteira; Território.

\begin{abstract}
This article aims to analyze and understand the importance of fieldwork in the academic education of professionals that works in Geography education, as well, to understand the construction of the different border realities between Brazil and Argentina, in the same way, to study the cultural aspects of the population. Studying the frontier, through field analysis, is fundamental to understand its settlement and formation process, as well to understand the relationships that are established between the territories. In this way, we used as a case of study the activities carried out during the fieldwork of Political Geography, from the graduation course of Geography, from the Federal University of Fronteira Sul, Campus Chapecó. Through fieldwork, it became possible to understand the different relationships between borders, as well, to expand knowledge in its multiple dimensions,

\footnotetext{
${ }^{1}$ Este estudo é fruto das atividades realizadas durante o trabalho do campo da disciplina de Geografia Política do Curso de Graduação em Geografia - Licenciatura da Universidade Federal da Fronteira Sul, Campus Chapecó.

${ }^{2}$ Acadêmico do Curso de Graduação em Geografia - Licenciatura da Universidade Federal da Fronteira Sul, Campus Chapecó. Bolsista de Iniciação Científica - CNPq. E-mail: gersonjrnaibo@outlook.com

${ }^{3}$ Acadêmica do Curso de Graduação em Geografia - Licenciatura da Universidade Federal da Fronteira Sul, Campus Chapecó. Bolsista do Programa Residência Pedagógica - CAPES. E-mail: shara_brunetto@hotmail.com

${ }^{4}$ Professor Adjunto do Curso de Graduação em Geografia - Licenciatura da Universidade Federal da Fronteira Sul, Campus Chapecó. E-mail: marlon.brandt@uffs.edu.br
} 
enabling the relationship between different areas of Geography, from the closest to the most distant. In this case, there is an intrinsic approach between the subject and the studied territory, expanding the capacities for understanding territorial dynamics. In this way, we can emphasize that fieldwork is essential to expand knowledge, providing solid elements for the formation of geographers.

Keywords: Geography teaching; Pedagogical ways; Fieldwork; Frontier; Territory.

Resumen: Este artículo tiene por objetivo analizar y comprender la importancia del trabajo de campo en la formación académica de los profesionales que actúan en el área de la enseñanza de Geografía, así como, conocer la construcción de las distintas realidades fronterizas entre Brasil y Argentina, de la misma manera que los aspectos culturales de la populación. Estudiar la frontera, por medio de análisis de campo, es fundamental para comprender su proceso de poblamiento y formación, bien como para el entendimiento de las relaciones que son establecidas entre los territorios. En este sentido, utilizamos como estudio de caso las actividades realizadas a lo largo del trabajo de campo de la asignatura de Geografía Política, del Curso de Grado en Geografía - Licenciatura de la Universidad Federal da Frontera Sur, Campus Chapecó. Través el trabajo de campo, fue posible comprender las diferentes relaciones entre las fronteras, además de ampliar el conocimiento en sus múltiples dimensiones, permitiendo una relación entre las diferentes áreas de la Geografía, desde las más cercanas hasta las más lejanas. En este caso, hay una aproximación intrínseca entre el sujeto y el territorio estudiado, ampliando las capacidades de comprensión de las dinámicas territoriales. Así, podemos destacar que el trabajo de campo es esencial para ampliar el conocimiento, propiciando elementos sólidos para la formación de los geógrafos.

Palabras Clave: Enseñanza de Geografía; Caminos pedagógicos; Trabajo de campo; Frontera; Territorio.

\section{Introdução}

O trabalho de campo é um importante instrumento metodológico de ensinoaprendizagem, que desempenha um indispensável papel no ensino da Geografia escolar e universitária, bem como em outras disciplinas e áreas da ciência. Nesse sentido, o objetivo proposto neste artigo, é analisar e compreender a importância do trabalho de campo na formação acadêmica dos Licenciados em Geografia, assim como, conhecer a construção das distintas realidades fronteiriças entre Brasil e Argentina, da mesma maneira que os aspectos culturais da população.

Neste artigo, analisamos o trabalho de campo como um instrumento metodológico de ensino e pesquisa, utilizado para compreender os territórios fronteiriços, ou seja, espaços que historicamente foram constituídos por meio das relações e dinâmicas sociais, econômicas, políticas e culturais. Portanto, estudar a fronteira, por meio da análise de campo é fundamental para compreender o seu processo de povoamento e formação, bem como, para o entendimento das relações que são estabelecidas entre os territórios. 
EM

Esse artigo encontra-se dividido em três partes. Nas duas primeiras seções, realizamos breves discussões teórico-conceituais acerca do trabalho de campo enquanto metodologia de ensino-aprendizagem e sobre as relações fronteiriças no ensino de Geografia. Na última seção, apresentamos os encaminhamentos metodológicos acompanhado das conclusões e considerações finais.

\section{Trabalho de campo, sua essência e importância para o ensino de Geografia}

O trabalho de campo ao longo dos anos desempenhou diversas funções, todas de extrema relevância nas áreas da pesquisa e do ensino geográfico. Desde a sua constituição enquanto ciência, tal metodologia foi fundamental na descrição e observações da paisagem, pelos naturalistas. Ao longo da trajetória do pensamento geográfico, os trabalhos de campo passaram a ser redesenhados, perdendo o viés puramente descritivo, assumindo um caráter mais crítico e migrando também para a prática do ensino da Geografia. Conforme Rodrigues e Otaviano (2001, p. 36), se tratando de "[...] um enfoque conceitual-pedagógico, considera-se que o trabalho de campo em sua forma e essência é um método relevante dentro do planejamento do ensino e ou em sua prática propriamente dita [...]".

Quando os alunos estão em campo, pesquisando e observando é imprescindível que a teoria e que os conceitos geográficos estudados estejam entrelaçados para a consolidação do conhecimento geográfico. De acordo com Alentejano e Rocha-Leão (2006, p. 57) "neste sentido, trabalho de campo não pode ser mero exercício de observação da paisagem, mas partir desta para compreender a dinâmica do espaço geográfico, num processo mediado pelos conceitos geográficos".

Estar em um trabalho de campo é um momento importante para a formação e constituição dos profissionais do ensino em Geografia, pois mesmo estudando o fenômeno em sala, a prática do campo apresenta a possibilidade de abordar diferentes fatores que a teoria em sala não nos proporciona, por isso à relação entre teoria e prática, como ressaltada por Marcos (2006, p. 106):

O trabalho de campo enquanto um instrumento de pesquisa dos mais importantes para a produção do conhecimento geográfico, momento em que o tema de estudo se desvenda diante dos olhos e obriga a estarmos atentos, de modo a que nada fuja à investigação. É preciso olhar com profundidade e observar, sobretudo aquilo que não havíamos considerado antes de sair para campo. 
EM

Partindo desta perspectiva, a aula de campo, primordialmente, apresenta-se não apenas como algo complementar a teoria estudada em sala de aula, mas sim, como algo para além deste espaço. Desta forma, o trabalho de campo não se limita a comprovação das teorias e conceitos estudados, sendo uma atividade interdisciplinar que busca conectar diversos conhecimentos em um conjunto de observações e sistematização de pensamentos. Conforme argumenta Naibo et al. (2018, p. 140):

A dinâmica de campo permite também que se observa o onde o material estudado se insere, trazendo uma abrangência maior de sua totalidade e de suas inter-relações e especificidades. Muda-se a visão genérica que se desenvolve em sala apenas com a apresentação de conceitos e conteúdos e faz com que o aluno tenha contato não apenas com o que foi estudado, mas que se utilize de suas noções geográficas, trabalhadas durante o desenvolvimento das noções básicas na escola [e universidade] para situá-la no espaço em que vive.

A prática de campo é uma atividade processual e construtivista que não se finda com a finalização da atividade in loco, mas sim, com o seu retorno à sala de aula como uma etapa de encerramento da atividade (OLIVEIRA e ASSIS, 2009). A atividade se conclui, mas o processo não se finaliza, pois por meio dele são estabelecidas novas relações e conexões de diálogo entre as próximas aulas e situações do cotidiano. Sendo assim, para Braun (2007, p. 262):

[...] a aprendizagem, a partir do contato direto com a realidade é uma ação pedagógica com grandes potencialidades e que na fase final, contempla a discussão e a consolidação dos conhecimentos através de registros, mapeamento e da síntese das conclusões.

Pedagogicamente, ensinar e aprender ocorre em tempo simultâneo, e esta assimilação acontece quando despertamos interesse pelo conjunto de conteúdos e atividades que são desenvolvidas. Desta forma, o trabalho de campo se apresenta como possibilidade para que o interesse seja despertado nos sujeitos desse processo de ensino e aprendizagem, sendo que as atividades de campo só são significativas quando há um envolvimento dos atores e proporciona uma mudança de pensamentos e atitudes. 
EM

QUESTÃO

V.13 N. $04 \bullet 2020$

pág. 96-110

\section{Relação fronteiriça e a sua aproximação com o aprender geográfico}

No ensino de Geografia, as fronteiras, bem como todos os conteúdos que derivam dessa temática são deficitárias, principalmente quando nos referimos a delimitações espaciais internacionais. Abarcando a temas da Geografia Política ou da Geopolítica, esses assuntos, na maioria das vezes são esquecidos ou deixados de lado. Salientamos que, tomando esse posicionamento, não estamos invisibilizando apenas um assunto, mas sim, um espaço, um território, um lugar e uma história, neste caso, nos referimos aos espaços fronteiriços como no caso da fronteira entre Brasil e Argentina. Espaços que ao longo da história foram alvo de disputas políticas entre os países, onde para Ferrari (2011, p.27) “[...] delimitar e separar territórios para dominá-los são atividades espaciais que, de acordo com a época histórica, formam parte da natureza social da espécie humana".

O espaço ao longo do tempo tem sido disputado para garantir o domínio de algumas nações, no qual passam os limites territoriais a serem definidos, com o objetivo de demarcar as terras de determinados Estados ou povos. Porém olhando para a fronteira, pode-se perceber que ela vai além de um espaço de separação, da construção de uma alteridade entre os "nós" e “eles", podendo ser também um ponto de encontro de culturas, como ressalta Machado (1988, p. 42):

[...] a fronteira é objeto permanente da preocupação dos estados no sentido de controle e vinculação. Por outro lado, enquanto a fronteira pode ser um fator de integração, na medida que for uma zona de interpenetração mútua e de constante manipulação de estruturas sociais, políticas e culturais distinta.

Quando os espaços de fronteira são analisados sistematicamente, pode-se perceber que para as pessoas que vivem e convivem nela, ela não impede que as relações de interação sejam estabelecidas. Nesse sentido, é possível entender a fronteira como uma criação política dos seres humanos pela necessidade de limitar o seu território e demonstrar poder. Porém, essa divisão nem sempre ocorre para aqueles que vivem próximos a elas. Nesse caso, essa linha artificial, longe de ser vista como uma barreira, seria mais um lugar de encontros.

Compreender a dinâmica dos espaços de fronteira principalmente com o processo de globalização, no qual as fronteiras passam a ser ressignificadas, torna-se uma atividade cada vez mais importante dentro do ensino de Geografia. Como ressalta Cavalcanti (2006, p. 28):

O mundo de hoje possui uma característica que é a expressão de uma dimensão espacial: a globalização. Entende-se a globalização como um fenômeno de eliminação de fronteiras entre países de todo o mundo, que 
afeta múltiplos campos: cultural, tecnológico, social, econômico etc., e o que traz como consequência a construção de espaços de relações integradas. Ainda que se saiba que a globalização é um processo complexo e diverso, no qual participam efetivamente muitos países, mas não todos, e que esta participação ocorre de modos diferenciados, pode-se dizer que todos experimentam, de fato, em muitos aspectos, uma integração e aproximação de espaços. É, assim, um fenômeno que obriga a considerar a interdependência de escalas, já que nele estão profundamente interrelacionados o local, o regional e o global.

\section{Caminhos pedagógicos para realização do trabalho de campo}

Neste trabalho, utilizamos as atividades realizadas durante o trabalho do campo da disciplina de Geografia Política, do Curso de Graduação em Geografia - Licenciatura, da Universidade Federal da Fronteira Sul, Campus Chapecó. A atividade de campo foi organizada em três etapas: 1) pré-campo: aula sobre a formação de fronteiras, estudo dos espaços visitados e elaboração de um roteiro de campo e de uma sequência de questionamentos para a realização de entrevistas; 2) trabalho de campo in loco: ocorrido no dia sete de julho de 2017, no qual, visitou-se a área urbana dos municípios de Itapiranga - SC, Dionísio Cerqueira - SC, Barracão - PR e Bernardo de Irigoyen (Misiones-Argentina). Nesta etapa da atividade foram realizadas conversas com moradores e comerciantes locais, e observações dos espaços fronteiriços, e 3) pós-campo: sistematização das observações com a produção de um relatório dissertativo e proposição de um planejamento pedagógico para aplicação na educação básica sobre o tema.

Nos próximos elementos do texto, apresentamos as observações do trabalho de campo in loco, juntamente com uma introdutória revisão bibliográfica levantada acerca dos locais visitados, com o objetivo de dar suporte teórico-conceitual acerca da temática e dos espaços estudados.

Relação Fronteiriça entre Dionísio Cerqueira (BR) e Bernardo de Irigoyen (ARG)

Para compreender o processo de povoamento e a formação dos municípios do Oeste de Santa Catarina, é importante relacioná-lo ao contexto histórico do qual faz parte. Ao longo da história e povoamento deste território, já eram estabelecidas relações entre os espaços de fronteiras. As relações fronteiriças se tornam mais intensas com o passar dos anos e desenvolvimento das atividades econômicas, sobretudo a partir da exploração comercial da 
EM

QUESTÃO

V.13 N. $04 \bullet 2020$

pág. 96-110

erva-mate em fins do século XIX. Nesse período, a instalação de ervateiras argentinas na região de Misiones, junto com a exploração dos ervais nativos em solo brasileiro, promoveu não apenas a migração de brasileiros para a região de fronteira no lado brasileiro, mas também o comércio ervateiro e uma intensa relação transfronteiriça entre os países (CORREA, 1970; FERRARI, 2011).

Espaço que historicamente foi alvo de disputas entre o Brasil e a Argentina na chamada Questão de Palmas ou Misiones, resolvida em 1895 e também entre o Paraná e Santa Catarina no que ficou conhecido como Questão do Contestado (FERRARI E DIAS, 2011). Situações que, até sua resolução exerceram um importante papel na sua dinâmica espacial. Para demarcar o território era preciso povoá-lo. Se no início a ocupação ocorria de modo difuso, numa "sorrateira infiltração", para utilizar o termo sugerido por Queiroz (1981) a respeito da relação da erva-mate com o povoamento da região por parte do lado brasileiro, seria somente a partir do final do término da Questão do Contestado, em 1916, que a fronteira Oeste brasileira passaria a ser ocupada de maneira mais intensa, com a colonização promovida por teuto e ítalo-brasileiros, proveniente, em sua maioria, do Rio Grande do Sul (NODARI, 2009).

A medida que o povoamento da região fronteiriça se intensificava e diferentes políticas de controle da fronteira foram promovidas pelos Estados, sobretudo em relação ao fluxo de produtos, aumentou-se a fiscalização, o que acabou prejudicando os fluxos e o comércio transfronteiriço. No entanto, apesar das políticas fronteiriças e a busca por mais controle desses espaços, com a construção e intensificação de barreiras de fiscalização, a interação entre os dois países não deixou de ocorrer, sobretudo em cidades com fronteira seca ou vizinhas, como no caso de Dionísio Cerqueira e Barracão do lado brasileiro e Bernardo de Irigoyen do lado argentino. Essa proximidade pode ser vista, por exemplo, na Figura 1, que traz uma imagem de satélite ilustrando essa aproximação, que sem a delimitação política separando os países se apresenta como apenas uma cidade. 
Figura 1 - Imagem de satélite dos municípios de Barracão, Dionísio Cerqueira e Bernardo de Irigoyen.

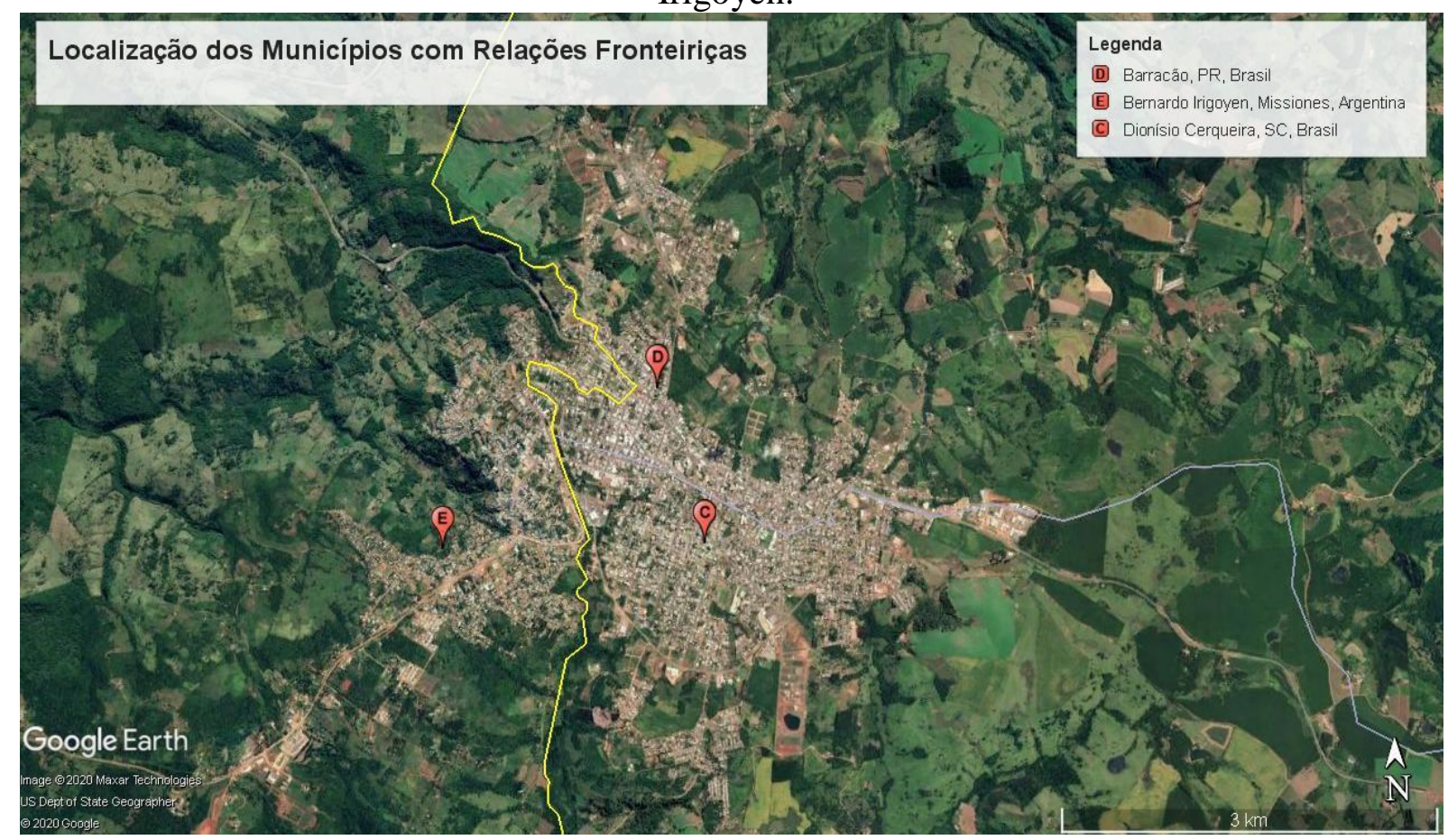

Fonte: Google Earth, adaptado por Tiago Wilian Rocha Dalmora (2020).

De acordo com Ferrari e Dias (2011), embora estes espaços sejam regidos e administrados por países diferentes, a população interage diariamente, pelo uso e apropriação do espaço. Em campo, percebemos uma intrínseca interação entre os municípios do Sudoeste do Paraná e Oeste de Santa Catarina e também entre Brasil e Argentina, onde se constatou também que muitos moradores trabalham e moram em cidades distintas, ou seja, esta relação de ocupação e apropriação do espaço é algo que se intensifica em regiões fronteiriças. Concorda-se assim com Souza, (2011, p. 21) para quem as "fronteiras expõem complexidades sociais. Exibem fluxos de pessoas, mercadorias e informações inter-territoriais. São áreas de influências culturais ora mais ou menos intensas". Observamos também a livre travessia do limite territorial entre o Brasil e Argentina, esta travessia é facilitada por ser um limite seco. Neste espaço fronteiriço a interação entre moradores e comerciantes dos diferentes países faz parte do cotidiano destes municípios. A Figura 2 mostra um trecho dessa fronteira seca, onde foi possível observar o livre trânsito de moradores entre o Brasil e a Argentina e vice-versa, muitos deles carregando sacolas de compras. O Fluxo comercial também pode ser observado na presença de casas comerciais dos dois lados da fronteira, como é possível observar na Figura 3, que mostra um anúncio de preços em um estabelecimento do lado brasileiro. 
Figura 2 - Visita a Fronteira Seca Brasil/Argentina em Dionísio Cerqueira/Bernardo de Irigoyen.

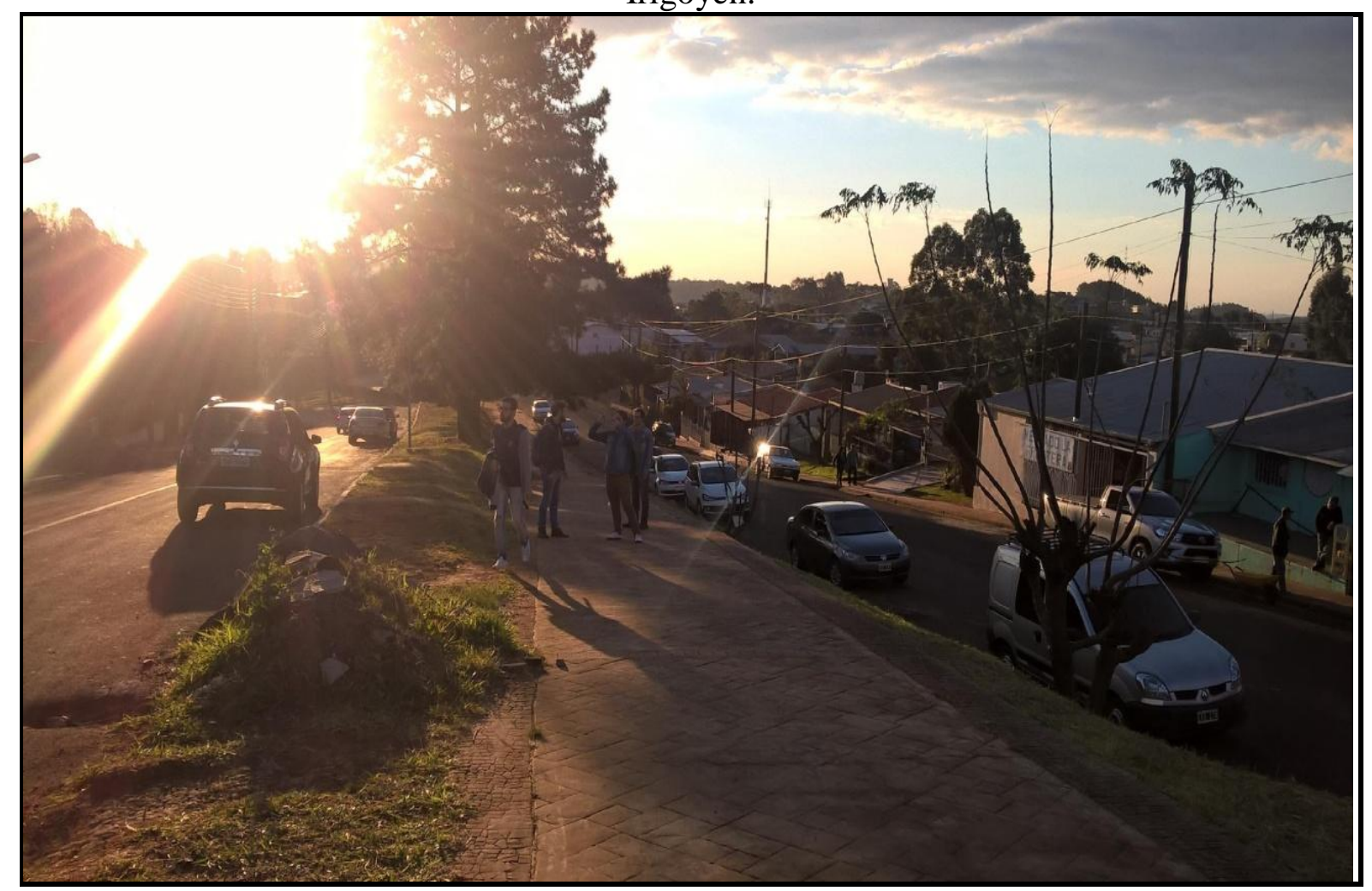

Fonte: dos autores, 2017.

Um elemento que pode ser observado na fronteira é o modo em que esta é afetada pelas flutuações políticas e econômicas dos países vizinhos. Essa, no caso brasileiro e argentino está relacionada, por exemplo, ao valor do câmbio, que pode favorecer ora comerciantes argentinos, ora comerciantes brasileiros. Em 2017, observamos no campo um maior fluxo de argentinos realizando compras do lado brasileiro. Isso pode ser percebido não somente pela presença de automóveis ou da conversa em espanhol nos supermercados e lojas locais, mas também no uso do idioma para anunciar os produtos. Um desses exemplos pode ser observado nesse comércio, que se encontra na fronteira seca, em frente ao lado argentino. Nele não apenas os preços estão em pesos, mas os próprios cortes de carne se encontram traduzidos no idioma do país vizinho. Isto retrata a alta circulação de pessoas de nacionalidade argentina no mercado comercial brasileiro. Por meio dessa imagem, podemos perceber o interesse que os comerciantes brasileiros têm em estabelecer a circulação de mercadorias entre os países. 
Figura 3 - Propaganda comercial em estabelecimento do lado brasileiro.

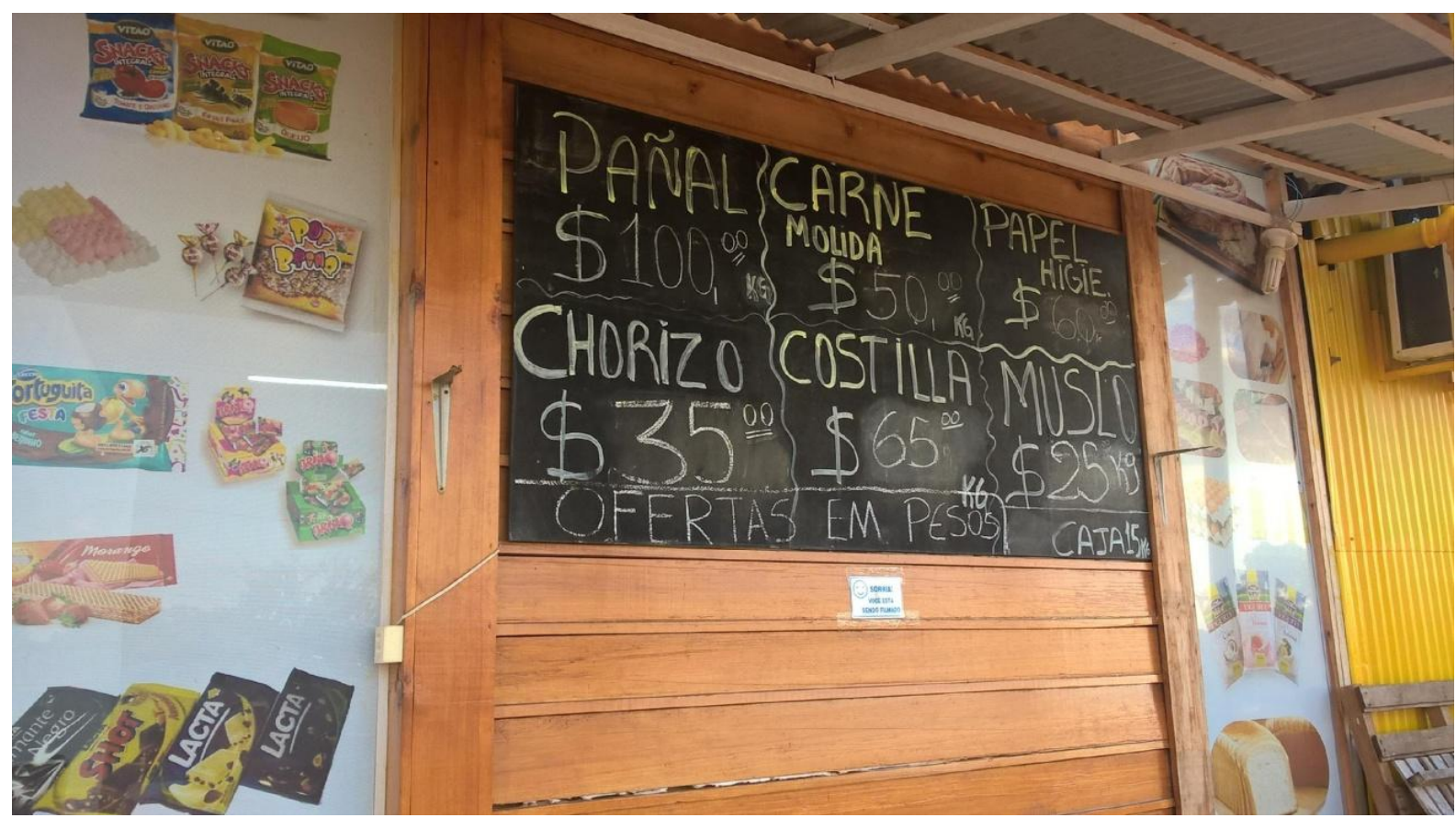

Fonte: dos autores, 2017.

Um elemento que pode ser observado na fronteira é o modo em que esta é afetada pelas flutuações políticas e econômicas dos países vizinhos. Essa, no caso brasileiro e argentino está relacionada, por exemplo, ao valor do câmbio, que pode favorecer ora comerciantes argentinos, ora comerciantes brasileiros. Em 2017, observamos no campo um maior fluxo de argentinos realizando compras do lado brasileiro. Isso pode ser percebido não somente pela presença de automóveis ou da conversa em espanhol nos supermercados e lojas locais, mas também no uso do idioma para anunciar os produtos. Um desses exemplos pode ser observado nesse comércio, que se encontra na fronteira seca, em frente ao lado argentino. Nele não apenas os preços estão em pesos, mas os próprios cortes de carne se encontram traduzidos no idioma do país vizinho. Isto retrata a alta circulação de pessoas de nacionalidade argentina no mercado comercial brasileiro. Por meio dessa imagem, podemos perceber o interesse que os comerciantes brasileiros têm em estabelecer a circulação de mercadorias entre os países.

\section{Relações Fronteiriças entre Itapiranga (BR) e El Soberbio (ARG)}

Para entender as relações fronteiriças é necessário realizar um movimento de olhar ao processo colonizatório no qual as cidades foram constituídas, e é nesse sentido que o município de Itapiranga e a sua relação com a Argentina devem ser analisados, ou seja, olhando para o contexto em que ela foi sendo construída. De acordo com Mayer (2015) é 
importante enfatizar que a empresa dona das terras de Porto Novo, no qual hoje está localizado o município de Itapiranga - SC, era a chamada Volksverein - Sociedade União Popular para Alemães Católicos no Rio Grande do Sul, fundada em 1912 pelos jesuítas na cidade de São Leopoldo - RS, sendo a primeira a trazer essa forma de colonização para Santa Catarina.

A região em que está localizada se caracteriza por fazer fronteira com a Argentina e também por estar às margens do rio Uruguai, todavia a outra característica que chama atenção no processo de colonização do município acima referido é que o "empreendimento colonizador de Porto Novo possuía a peculiaridade de aceitar somente migrantes de origem germânica e católica [...]”. (FRANZEN, 2014. p.82).

Atualmente ainda é possível perceber a predominância da cultura alemã, devido a sua histórica colonização. A partir da prática de campo, constatamos que a língua alemã no município era e ainda é em alguns locais um dos principais critérios para se inserir no mercado de trabalho, todavia, a chegada de agroindústrias possibilitou a inserção de alguns imigrantes.

No decorrer da atividade realizada na cidade, foi possível observar que a relação que existe entre os moradores de Itapiranga com a fronteira da Argentina, é bem distinta das constatadas em Dionísio Cerqueira. Os moradores possuem pouco contato com o outro lado da fronteira. A principal relação estabelecida entre estes dois países é dada pela reserva florestal de Yabotí, que se apresenta como uma barreira natural de contato entre as diferentes nacionalidades, como pode ser visto na Figura 4. Entretanto, foi possível constatar que a relação comercial dos moradores do município de Itapiranga com o mercado argentino é o mesmo estabelecido pelos outros municípios do Oeste de Santa Catarina. Muitos moradores se dirigem ao lado argentino pela fronteira seca, via Dionísio Cerqueira, para ter acesso aos estabelecimentos comerciais de Bernardo de Irigoyen.

Uma das características que constatamos foi à relação estabelecida entre os moradores de Itapiranga com a reserva florestal de Yabotí, para realização de atividades esportivas como a caça e pesca, mesmo sabendo da ilegalidade e de seus riscos. De acordo com moradores entrevistados, esta relação entrou em declínio nos últimos anos, devido à fiscalização e a um assassinato de três catarinenses que ocorreu na reserva florestal da Argentina ${ }^{5}$.

\footnotetext{
${ }^{5}$ Segundo a notícia publicada na plataforma virtual do Portal NSC Total no dia 14 de janeiro de 2009, os corpos de três homens catarinenses foram encontrados mortos na reserva florestal de Yabotí, na Argentina. Os corpos estavam desaparecidos desde o dia 26 de dezembro de 2008.
} 
Figura 4 - Delimitação territorial do Brasil e Argentina.

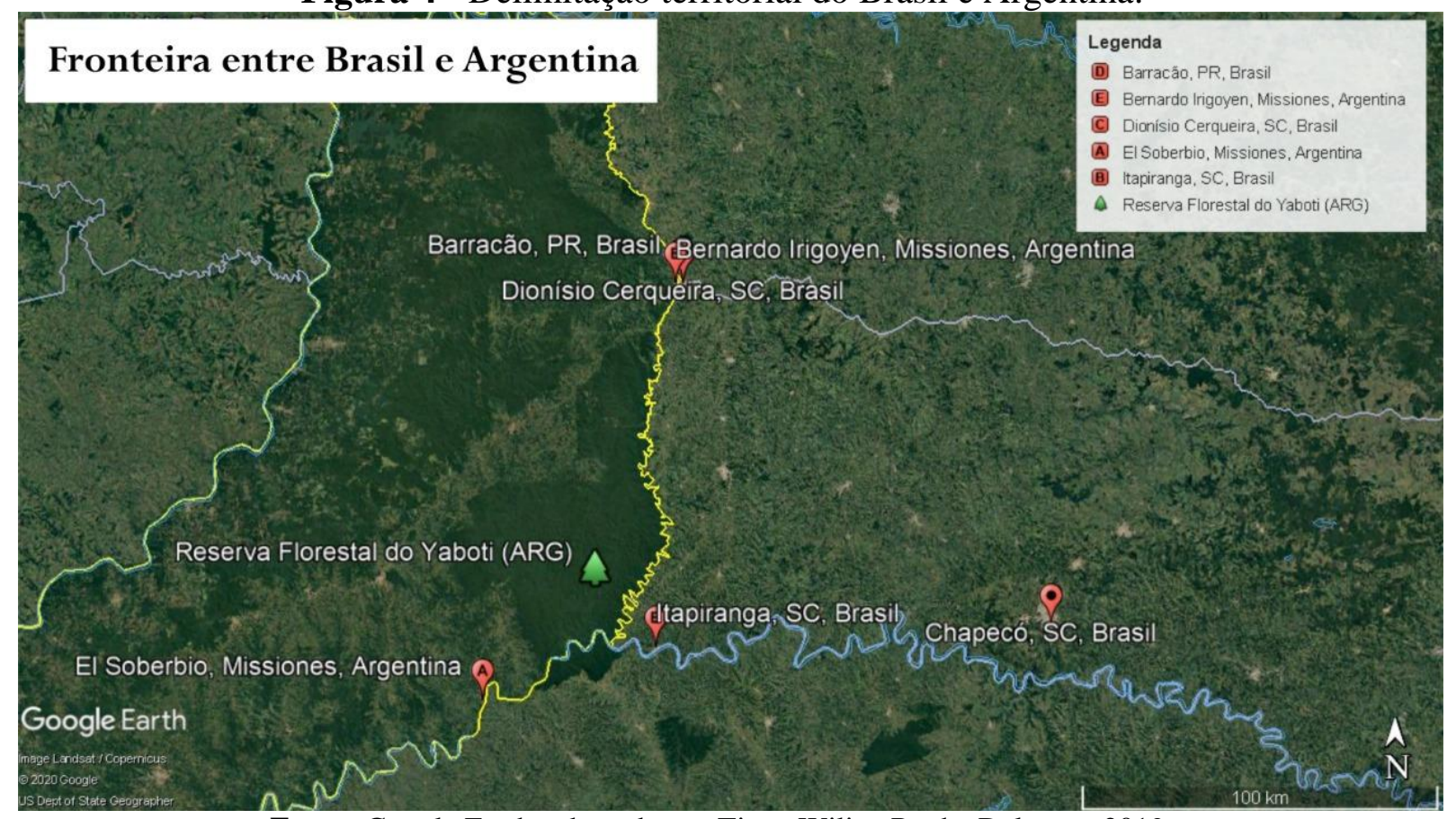

Fonte: Google Earth, adaptado por Tiago Wilian Rocha Dalmora, 2019.

\section{Considerações finais}

Com a realização deste artigo, procuramos demonstrar, através do estudo de caso das relações fronteiriças entre o Brasil e a Argentina a importância da utilização do trabalho de campo como uma metodologia de ensino-aprendizagem na Geografia. Por meio desta atividade, foi possível perceber uma maior aproximação dos alunos às temáticas estudadas, além de uma melhor compreensão das relações das fronteiras, pois quando é realizado o trabalho de campo e a observação in loco torna-se possível compreender as diferentes relações na fronteira, bem como ampliar o conhecimento em suas múltiplas dimensões, possibilitando assim a relação entre as diferentes áreas da Geografia. Neste caso, há uma aproximação intrínseca entre o sujeito e o território estudado, ampliando as capacidades de compreensão das dinâmicas territoriais. Deste modo, podemos salientar que o trabalho de campo é essencial para ampliar o conhecimento, dando elementos sólidos para a formação dos geógrafos.

Na perspectiva da formação de professores de Geografia, foram interrogados no póscampo alguns acadêmicos que participaram do trabalho de campo em questão, com a finalidade de destacar algumas contribuições na formação dos professores de Geografia, sobre a sua participação enquanto acadêmico e posteriormente em sua utilização em sala de aula. Nesse sentido, um dos acadêmicos participantes do trabalho do campo afirmou que, 
EM

[...] a atividade permitiu a realização de análises e interpretação das relações transfronteiriças in loco. Por meio dela podemos perceber como essas relações ocorrem (ou não) de modos diferentes nos lugares e como elas refletem na organização daquele espaço geográfico, desde relações comerciais, econômicas e populacionais e quais fatores as impulsionam. $\mathrm{O}$ trabalho de campo é de fundamental importância para a compreensão do espaço geográfico, e nós, enquanto professores de Geografia, precisamos nos apropriar dessa metodologia desde a educação básica. Sem trabalho de campo não há Geografia.

E ainda, segundo outra participante,

[...] o trabalho de campo na tríplice fronteira demonstra na prática/na visualização e vivência, aquilo que entendemos enquanto ampla espacialização de relações, cultura, sociedade e modos econômicos e políticos presentes em cada lugar, isso porque as três fronteiras (materiais ou não) demonstram como cada lugar tem em sua formação uma realidade própria e como essas passam a se relacionar no espaço-tempo (como se uma cidade estivesse dentro da outra), principalmente no que diz respeito às trocas comerciais. Assim, entendo que as relações transfronteiriças em Dionísio Cerqueira, Barracão e Bernardo de Irigoyen são importantes na formação do professor de geografia pois serve como "material" orgânico dessa dinâmica constante de relações entre países e entre estados. Culturalmente falando, acredito que é um campo que nos provoca a pensar também sobre até onde a fronteira física e o "controle" político dos lugares separa de fato essa troca de saberes, costumes e tradições das diferentes cidades visitadas.

Em diálogo com os acadêmicos percebemos que o trabalho de campo é uma etapa fundamental nos processos de ensino-aprendizagem da Geografia, tanto em nível básico de ensino quando em nível universitário. No que diz respeito à pesquisa enquanto forma de investigação e estudo esse processo também é indispensável. Desta forma, compreendemos que atividades de campo como as descritas neste trabalho, para além de uma atividade de ensino, está também se configura em uma atividade de pesquisa, o que a torna mais proveitosa, visto que possibilita analisar concretamente as relações estabelecidas.

\section{Referências}

ALENTEJANO, P. R. R. y ROCHA-LEÃO, O. M. (2006). Trabalho de campo: uma ferramenta essencial para os geógrafos ou um instrumento banalizado?. São Paulo: Boletim Paulista de Geografia.nº 84, pp. 51-67.

BRAUN, A. M. S. (2007). Rompendo os muros da sala de aula: o trabalho de campo na aprendizagem de geografia. Santa Cruz do Sul: Ágora, , v. 13, n. 1, pp. 250-272. 
EM

QUESTÃO

V.13 N. $04 \bullet 2020$

pág. 96-110

CAVALCANTI, L. S. (2006). Bases teórico-metodológicas da geografia: uma referência para a formação e a prática de ensino. In: CAVALCANTI, Lana de Souza (Org.). Formação de professores: concepções e práticas em geografia. Goiânia: falta a Editora,pp. 27-49.

CORRÊA, R. L. (1970). O sudoeste paranaense antes da colonização. Rio de Janeiro: Revista Brasileira de Geografian. 1, ano 32, pp. 87-98.

FERRARI, M. y DIAS, L. C. (2011). Territorialidades transfronteiriças na zona de fronteira seca internacional Brasil-Argentina. In: DIAS, L. C.; FERRARI, M. (Org.). Territorialidades humanas e redes sociais. Florianópolis: Insular.

FERRARI, M. (2011). Interações transfronteiriças na zona de fronteira Brasil-Argentina: o Extremo Oeste de Santa Catarina e Paraná e a província de Misiones (Século XX e XIX). Tese (Doutorado em Geografia) - Universidade Federal de Santa Catarina, Programa de pósgraduação em Geografia, Florianópolis, Brasil.

FRAZEN, D. O. (2014) A sucessão familiar na propriedade agrícola: estudo de caso numa colonização do extremo oeste catarinense (1926-1960). Passo Fundo: Revista Semina, v.13, n.1, pp. 81-94.

MACHADO, L. O. (1998). Limites, Fronteiras, Redes. In: DUTRA, V. S. et al. (Org.). Fronteiras e Espaço Global. Porto Alegre: AGB, pp.41-49.

MARCOS, V.. (2006). Trabalho de campo em geografia: reflexões sobre uma experiência de pesquisa participante. São Paulo: Boletim Paulista de Geografia, , nº 84, p. 105-136.

MAYER, L. (2015). Repressão em Itapiranga (SC) durante o Estado Novo (1937 - 1945. In: XXVIII SIMPÓSIO NACIONAL DE HISTÓRIA., Florianópolis: Anais eletrônico. Disponível em: <http://www.snh2015.anpuh.org/resources/anais/39/1433936901_ARQUIVO_REPRESSAO EMITAPIRANGA.pdf >. Acesso em: 27 de set. 2019.

NAIBO, G. J. et al. (2018). A aula de campo como metodologia de ensino-aprendizagem de geografia. In: ALVES, S. A (Org.). PIBID UFFS: contribuições à formação docente. Toledo: Vivens, pp. 137-14.

NODARI, E. S. (2009). Etnicidades renegociadas: práticas socioculturais no Oeste de Santa Catarina. Florianópolis: Editora das UFSC.

OLIVEIRA, C. D. M; ASSIS, R. J. S. (2009). Travessias da aula em campo na geografia escolar: a necessidade convertida para o além da fábula. São Paulo: Educação e Pesquisa, v. 35, n. 1, pp. 195-209.

PORTAL NSC TOTAL. (2018). Corpos dos três catarinenses assassinados na Argentina continuam na mata. Disponível em: <https://www.nsctotal.com.br/noticias/corpos-dos-trescatarinenses-assassinados-na-argentina-continuam-na-mata>. Acesso: 28 jan. 2018.

QUEIROZ, M. V. (1981). Messianismo e conflito social: a Guerra Sertaneja do Contestado,1912-1916. 2. Ed. São Paulo: Ática. 
RODRIGUES, A. B.; OTAVIANO, C. A. (2001). Guia Metodológico de Trabalho de Campo. Londrina: Geografia, v. 10, n. 1, pp. 35-43.

SOUZA, R. J. D. (2011). Fronteiras ou Raias (?) In: PASSOS, M. M. (Org.). A raia divisória: São Paulo, Paraná, Mato Grosso do Sul (Cenas e cenários). 1. ed. São Paulo: Outras Expressões, pp. 17-42. 